\title{
Measuring the risk factors for postpartum depression: development of the Japanese version of the Postpartum Depression Predictors Inventory-Revised (PDPI-R-J)
}

Mari Ikeda* and Kiyoko Kamibeppu*

\begin{abstract}
Background: Postpartum depression (PPD) is a global phenomenon. Depression in the first month following delivery is experienced by $20 \%$ of mothers in Japan. Therefore, a screening instrument that identifies the risk for depression during pregnancy and in the early postpartum period is required for primary prevention. The aims of this study were to develop the Japanese version of the Postpartum Depression Predictors Inventory-Revised (PDPI-R-J) and determine its predictive validity during pregnancy and one month after delivery.

Methods: In order to develop the inventory, two bilingual translators translated the PDPI-R into Japanese. Then, back translation was done and a thorough discussion with the original developer was conducted in order to establish semantic equivalence. After the PDPI-R-J was developed, the study used a prospective cohort design. A total of 84 women in their eighth month of pregnancy participated in the study. Seventy-six mothers completed the PDPI-R-J at the first month after childbirth. Women were diagnosed using Mini-International Neuropsychiatric Interview (M.I.N.I.) to determine the presence of minor or major depression at the first month after childbirth and the receiver operating characteristic curve was plotted to evaluate the predictive capacity of PDPI-R-J.
\end{abstract}

Results: Of the 76 mothers who completed the PDPI-R-J during the first-month assessment, 16 mothers (21\%) met the PPD criteria. The prenatal version of the PDPI-R-J administered during pregnancy accurately predicted $62.8 \%$ of PPD (95\% Cl 0.48-0.77) and the postpartum version administered at the first month after delivery predicted $82.0 \%$ of PPD (95\% Cl 0.71-0.93). The cutoffs identified were 5.5 for the prenatal version and 7.5 for the postpartum version. The PDPI-R-J postpartum version, which includes items relating to the infant, increased the predictive validity of PPD (0.67 to 0.82). Comments from the participants included that the use of the PDPI-R-J enhanced the chance to openly communicate about their history and risks for depression with the researchers, if any existed.

Conclusions: The PDPI-R-J was found to be a useful and valid screening tool for predicting PPD. Both the prenatal and postpartum versions should be continuously administered to mothers because delivery and infant-related factors affect the potential for PPD.

Keywords: Japanese, Postpartum depression, Risk factors, ROC analysis, Screening instrument

\footnotetext{
* Correspondence: maritake-tky@umin.ac.jp; kkamibeppu-tky@umin.ac.jp Department of Family Nursing, Division of Health Science \& Nursing, Graduate School of Medicine, The University of Tokyo, 7-3-1 Hongo Bunkyo, Tokyo 1130033, Japan
} 


\section{Background}

Despite the stereotype that the perinatal phase is a period of contentment, women frequently experience adjustment difficulties and depressive symptoms during pregnancy and the postpartum period. Approximately $8.5 \%-11 \%$ of women experience either minor or major depression (mMD) during pregnancy. Furthermore, 19\% of women have mMD in the first 3 months following delivery [1]. A recent large-scale epidemiological study provided some evidence of increased risk for depression in the postpartum period compared with non-pregnant /non-postpartum women (adjusted odds ratio: 1.52; 95\% CI: 1.07-2.15) [2]. In Japan, depression is reported to occur in the first month following delivery in $20.4 \%$ of mothers [3].

Women experiencing postpartum depression (PPD) appear to be unhappy, irritable, and unable to cope; have negative feelings about themselves and their children; are anxious; have low libido; have marital problems; experience difficulties managing household tasks; are tearful; have physical symptoms, such as sleep and appetite disturbances; and display obsessional behavior [4]. The quality of life for such women and their families is severely compromised, which can result in marital breakdown [5]. In the most severe cases, women report fear of hurting themselves or their newborns [6].

Risk factors for PPD include previous depression, anxiety and depressive symptoms during pregnancy, stressful recent life events, lack of social support, and low self-esteem $[7,8]$. It is crucial that early and accurate identification and intervention occur in order to prevent long-term consequences for childbearing families and to prevent PPD from becoming a significant mental-health problem. A screening instrument that identifies the risk for depression during pregnancy and in the postpartum period would help to prevent aggravation of PPD even when it occurs. Since 1978, when the first checklist to identify the risk factors for PPD in pregnancy became available [9], several similar instruments have been developed. Currently, 12 available instruments are designed to assess the risk factors for PPD (Table 1). Most such instruments include items like histories of depression and social support [10-17]. The instruments that have been developed since the late 1990s include self-esteem items [14,15,17,18]. Boyce et al. (2001) developed the Vulnerable Personality Style Questionnaire (VPSQ) to reflect dimensions of personality that are associated with vulnerability to PPD [19]. The instrument by Webster et al. (2003) [16] combined prenatal, perinatal, and postnatal risk factors for PPD; however, this instrument is used in the postpartum period, not during pregnancy.

The Postpartum Depression Predictors InventoryRevised (PDPI-R) [20] is the only antenatal screening scale whose design has been based on the findings of meta-analyses $[21,22]$ and not solely on clinical experience. The PDPI-R was updated to allow the identification of further risk factors [23], and it was the first instrument to assess risk factors that occur during both pregnancy and the postpartum period. The PDPI-R was originally designed to be administered via an interview conducted by a clinician. The interview format provides

Table 1 Comparison of the PDPI-R with previous screening instruments

\begin{tabular}{|c|c|c|c|c|c|c|c|c|c|c|c|}
\hline Beck, 2001 & $\begin{array}{c}\text { Braverman } \\
\text { et al., } \\
1978\end{array}$ & $\begin{array}{c}\text { Petrick, } \\
1987\end{array}$ & $\begin{array}{c}\text { Boyer } \\
\text { et al., } \\
1990\end{array}$ & $\begin{array}{c}\text { Appleby } \\
\text { et al., } \\
1994\end{array}$ & $\begin{array}{c}\text { Stamp } \\
\text { et al., } \\
1996\end{array}$ & $\begin{array}{c}\text { Posner } \\
\text { et al., } \\
1997\end{array}$ & $\begin{array}{c}\text { Reid } \\
\text { et al., } \\
1998\end{array}$ & $\begin{array}{l}\text { Boyce } \\
\text { et al., } \\
2001\end{array}$ & $\begin{array}{c}\text { Webster } \\
\text { et al., } \\
2003\end{array}$ & $\begin{array}{l}\text { Austin } \\
\text { et al., } \\
2005\end{array}$ & $\begin{array}{c}\text { Bernazzani } \\
\text { et al., } \\
2005\end{array}$ \\
\hline PDPI-R & * & * & * & ASQ & MASQ & $\mathrm{AQ}$ & ALPHA & VPSQ & VPDI & PRQ & CAME \\
\hline Marital status & $x$ & & & & & & & & & & \\
\hline Socioeconomic status & & & $x$ & & & $x$ & & & & & \\
\hline Self-esteem & & & & & & $x$ & $x$ & & & $x$ & $x$ \\
\hline Prenatal depression & & & $x$ & $x$ & & $x$ & $x$ & & & $x$ & \\
\hline Prenatal anxiety & & $x$ & $x$ & $x$ & & $x$ & & $x$ & & $x$ & \\
\hline Unwanted/unplanned pregnancy & $x$ & $x$ & $x$ & $x$ & & & $x$ & & & $x$ & $x$ \\
\hline Depression history & $x$ & $x$ & $x$ & $x$ & $x$ & $x$ & $x$ & & $x$ & $x$ & \\
\hline Social support & & $x$ & $x$ & $x$ & $x$ & $x$ & $x$ & & $x$ & $x$ & $x$ \\
\hline Marital relationship/satisfaction & $x$ & & $x$ & $x$ & $x$ & $x$ & $x$ & & & $x$ & $x$ \\
\hline Life stress & & $x$ & $x$ & $x$ & & & $x$ & & & $x$ & $x$ \\
\hline \multicolumn{12}{|l|}{ Childcare stress } \\
\hline Infant temperament & & & & & & & & & $x$ & & \\
\hline Maternity blues & & & & & & $x$ & & & $x$ & & \\
\hline
\end{tabular}

*no specific name was given to the instrument. 
a woman with an opportunity to discuss any problems she may be experiencing in relation to the risk factors [24]. The PDPI-R was adapted to enable women to complete the checklist themselves [25]. In that study, midwives were enthusiastic about the use of the PDPI-R, because pregnant women were given a chance to consider their responses before their perinatal consultation, and they appeared eager to explain them. Women were also pleased to have the opportunity to discuss their feelings and to consider their situations as being a normal occurrence. Thus, the PDPI-R enhanced communication between clinicians and women in need by focusing on their responses to the checklist questions.

The recent format of the PDPI- $\mathrm{R}$ is a self-report version with some follow-up questions. For example, if a woman has felt depressed during her current pregnancy, 1 point is assigned. The two follow-up questions (when/ how long, how severe), which are not scored, are asked if a woman answers that she has felt depressed during pregnancy. The purpose of knowing the timing, duration, and severity of depression is to provide clinicians with additional information to help them determine whether a woman needs a mental-health referral. The follow-up questions facilitate dialogue between women and clinicians. The original developer of the PDPI-R provided scoring directions for both the prenatal version and the postpartum version [24] and evaluated the psychometric properties of the PDPI-R [6]. The prenatal PDPI-R yielded a sensitivity of 0.76 and a specificity of 0.54 at a cutoff score of 10.5 (Beck et al. 2006). The predictive validity of the PDPI-R a screening instrument for PPD was determined in a large sample of Italian women [26]. The prenatal version of the PDPI-R administered during the $8^{\text {th }}$ month of pregnancy and the postpartum version administered during the $1^{\text {st }}$ month after delivery accurately predicted $78.2 \%$ and $83.4 \%$ of PPD, respectively. The cutoffs identified were 3.5 for the prenatal version and 5.5 for the postpartum version. The authors concluded that the PDPI- $\mathrm{R}$ is a useful and valid screening tool for PPD. The PDPI-R assesses individual risk factors, and the total score could be used to screen for PPD.

Our previous research has revealed evidence that in Japan, only $15 \%$ of hospitals perform maternal depression screening during the perinatal period; furthermore, only $9 \%$ of Japanese hospitals administer depression screening during the antenatal period [27]. In contrast, in the United States, $47 \%$ of women were screened for maternal depression during their prenatal visits [28]. Japanese women are advised to have prenatal visits every 4 weeks through 23 weeks gestation (instead of 27 weeks, as in the United States), every 2 weeks at 24-35 weeks gestation, and weekly after 36 weeks gestation for a total of 14 prenatal visits per low-medical-risk pregnancy [29]. In each prenatal visit, an appointment with the midwife follows the consultation with the obstetrician. It would be useful to utilize the frequent contact with women during the perinatal period to implement an adequate screening instrument that identifies the risk for depression during pregnancy; this would be a useful step in the primary prevention of PPD. The aims of this study were to develop a Japanese version of the PDPI-R (PDPI-R-J), to assess its reliability, and to evaluate its sensitivity, specificity, and predictive value as a screening instrument for PPD as compared with those of the PDPI-R over a range of cutoff scores.

\section{Methods}

\section{Setting and participants}

The setting for this study was a university hospital. All primipara women who were planning to give birth at the university hospital were potentially eligible for the study. In the first phase of recruitment, we explained the aims of the study and asked women who were present at the antenatal class (Mother Class) if they were willing to participate. The data were collected from October 2009 to September 2010. Out of 135 eligible women, 91 gave written informed consent (67.4\%). Women who agreed to participate handed in application forms that they completed on site. Women who agreed received either an e-mail or a phone call from the first author (M.I.; the researcher) to schedule the baseline assessment. To be included in the study, a woman had to be in the $28^{\text {th }}-32^{\text {nd }}$ gestational weeks, married, carrying a single fetus, willing to sign an informed consent release form, and available to be contacted by either phone or e-mail. Exclusion criteria for the study were; age $<20$ years, multiparous, difficulty speaking Japanese, and judged by midwives/obstetricians to be at risk of mental instability. We were able to collect information only after a signed informed consent form was received; therefore, the sociodemographic characteristics of women who did not participate in the study were not available.

\section{Procedure and design}

This study used a prospective cohort design. The study began in the participant's $8^{\text {th }}$ month of pregnancy and ended at 1 month after childbirth. The prenatal version of the PDPI-R-J was administered at the $8^{\text {th }}$ month of pregnancy and the postpartum version at the $1^{\text {st }}$ month after childbirth. In each assessment, a short interview regarding each risk factor and follow-up questions was followed by the first author (MI). The Mini-International Neuropsychiatric Interview (M.I.N.I.) was administered by a trained psychologist in order to determine whether the subject met the DSM-IV criteria for mMD (the outcome measure) at 1 month after childbirth. 


\section{Risk factors assessment}

The 13-item original English version of the PDPI-R was translated into Japanese and then back-translated into English in order to reach semantic equivalence. The 13 PDPI-R factors included: (1) marital status (being single), (2) low socioeconomic status, (3) low self-esteem, (4) prenatal depression, (5) prenatal anxiety, (6) unintentional pregnancy, (7) prior depression, (8) lack of social support, (9) marital dissatisfaction, (10) life stress, (11) childcare stress, (12) infant temperament, and (13) maternity blues. The first ten predictors comprise the prenatal version of the PDPI$R$, whereas the last three risk factors are specific to the postpartum period. Total scores on the prenatal version of the PDPI-R range $0-32$. The PDPI-R postpartum version (prenatal plus postpartum versions) is used after delivery and includes all ten factors of the prenatal version plus three additional risk factors. Total scores on the PDPI-R postpartum version range $0-39$ [24]. The higher the score, the more risk factors the subject had for PPD.

Development of the Japanese version of PDPI-R (PDPI-R-J) Prior to data collection, we developed the PDPI-R-J. Semantic equivalence focuses on whether the connotative meaning of each item in the translated version of an instrument is identical to that of the original-language version [30]. Back-translation, which is the key to establishing semantic equivalence, was used to assure that the meaning of each item in the PDPI-R remained the same after translation into Japanese.

\section{Translation}

Two bilingual translators worked independently on translations. One of the translators had a linguistic sociology background, and the other was experienced in broadcasting translations.

\section{Committee approach}

The two Japanese versions were checked by the first author (MI), and multiple discussions were held with the translators regarding the discrepancies between the two versions; then, one combined version was created. The committee consisted of professionals who convened to discuss the content equivalence and semantic equivalence of the combined version. The members of the committee were two psychologists, a midwife with experience dealing with pregnant women, and two midwives in academic-research fields with experience using this kind of instrument. Any inconsistencies identified were discussed in the committee, comments from the translators were considered, and discussion took place again until consensus was reached.

\section{Back-translation}

The consensus version was translated back into English by a translator whose native language was English and who was unaware of the original wording of the instrument. The original and back-translated versions were then checked for discrepancies by the researcher and then referred to the original developer of the PDPI-R for discussion. The original developer introduced a few discussion points, which were also addressed. The following content illustrates some of the discussions and decisions.

"Cohabitating" was combined with 'married' in the original version to mean "having a stable partner." However, in Japan, very few couples live together without being officially married. "Cohabitating" usually does not connote a stable relationship-rather, it represents more of a temporary association. Therefore, we decided to exclude the word "cohabitating."

We paraphrased the term "socioeconomic status" to "kurashi-muki," which means "daily life circumstances," because the purpose here is to discover the respondents" perceived financial status. We restated "be comfortably off" as "high" and "narrow circumstances" as "low."

The original version of the self-esteem item, "feel good about yourself," was very difficult to translate into Japanese. The Japanese word for "good" has a nuance of evaluation against others instead of against an individual's own standard. Thus, we phrased it, "Do you like yourself?" to determine whether one likes oneself (i.e., whether or not one is content with oneself, not whether or not others think one is "good").

The question asked in the postpartum version, "Does your baby cry much?" was a question often used by the health visitors during home visits to see if the babies were in good health. Therefore, we paraphrased it to "Do you have a hard time soothing the crying baby?"

Assessment questions of social support in the PDPI$\mathrm{R}$ were very particular. The word "confide," which means to tell a trusted person about personal things, was used. We therefore translated this to "kokoro-nouchio-uchiakeru," meaning "open your heart" to a trusted person.

We conducted a pretest using the preliminary version and gave it to six mothers for comments. Then, we finalized the Japanese version of the scale.

\section{Outcome measure: major or minor depression (mMD)}

The severity of depressive symptoms was assessed for all participants using the M.I.N.I., which was administered by a trained psychologist. The M.I.N.I. is a short, structured diagnostic interview that was developed jointly by psychiatrists and clinicians in the United States and Europe to detect DSM-IV and ICD-10 psychiatric 
disorders [31]. With an administration time of approximately 15 minutes, it was designed to meet the need for a short but accurate structured psychiatric interview for multicenter clinical trials and epidemiology studies and to be used as a first step in outcome tracking in nonresearch clinical settings.

\section{Statistical analysis}

Data are presented as means and percentages. The frequencies of endorsement of dichotomous PDPI-R-J items were compared between the $8^{\text {th }}$ month of pregnancy and the $1^{\text {st }}$ month postpartum using McNemar's test, while the means of PDPI-R-J items were compared using paired $t$-tests. Logistic analysis was performed in order to establish the relationships between each risk factor of the PDPI-R-J and the occurrence of postpartum mMD. Internal consistency reliability was estimated using Cronbach's alpha. Factor-to-factor and factor-tototal scale correlations were estimated to determine construct validity. Receiver operating characteristic (ROC) analysis was conducted to determine the cutoffs of the PDPI-R-J scores for the prenatal and postpartum versions. In ROC analysis, sensitivity and specificity are plotted over the range of cutoff points [32]. The area under the curve (AUC) represents the accuracy of the instrument in predicting which women will or will not have PPD. The following interpretation of AUC values is traditional: AUC $<0.7$ suggests "low" diagnostic accuracy, AUC 0.7-0.9 "moderate" diagnostic accuracy, and AUC > 0.9 "high" diagnostic accuracy [33]. Analyses were conducted using IBM SPSS Statistics version 20 .

\section{Ethical considerations}

Each participant was informed about the purpose of the study both verbally and in writing, and we guaranteed that their information would be treated confidentially. We informed them that their participation in the study was voluntary and that refusal to participate would not disadvantage them. We also informed them that they could withdraw from the research if they wished. The study protocol and the assessment procedures were reviewed and approved by the Ethics Committee of the University of Tokyo.

\section{Results}

\section{Participant characteristics}

Of the 91 who gave their consent to participate, 7 women were hospitalized due to imminent abortion and could not participate in the baseline assessment. Of the 84 enrolled women, 2 did not complete the $1^{\text {st }}$ month postpartum assessment (one was hospitalized due to severe PPD, and the other wished to withdraw from the research). Of the 82 women who completed the $1^{\text {st }}$
Table 2 Characteristics of the participants completed the assessment at one month after delivery $(\mathrm{N}=76)$

\begin{tabular}{|c|c|c|}
\hline \multirow{2}{*}{$\begin{array}{l}\text { Age, mean (SD) } \\
\text { Age range, years }\end{array}$} & \multicolumn{2}{|c|}{$33.4(4.5)$} \\
\hline & & \\
\hline \multicolumn{3}{|l|}{ Marital status, n (\%) } \\
\hline Married/partnered & 76 & $(100.0)$ \\
\hline Single & 0 & $(0.0)$ \\
\hline \multicolumn{3}{|l|}{ Employment status, n (\%) } \\
\hline Employed & 36 & $(47.4)$ \\
\hline Part-time & 5 & $(6.6)$ \\
\hline Housewife & 35 & $(46.1)$ \\
\hline \multicolumn{3}{|l|}{ Educational level, n (\%) } \\
\hline High school & 10 & $(13.2)$ \\
\hline Community College & 12 & $(15.8)$ \\
\hline University degree & 48 & $(63.2)$ \\
\hline Graduate school degree & 6 & (7.9) \\
\hline \multicolumn{3}{|l|}{ Socioeconomic status, n (\%) } \\
\hline Low & 0 & $(0.0)$ \\
\hline Medium & 52 & $(68.4)$ \\
\hline High & 14 & $(18.4)$ \\
\hline
\end{tabular}

month postpartum assessment, 6 were excluded for ineligibility (three were multiparous, two had premature delivery, and one gave birth to an infant with a congenital disorder). The sociodemographic characteristics of the sample are reported in Table 2. The participants' mean age was 33.4 years $(\mathrm{SD}=4.5) ; 71.1 \%, 100 \%, 54 \%$, and $76.8 \%$ had a university or graduate degree, were married or had a partner, were employed outside the home, and had medium or high socioeconomic status, respectively. Of the 76 women who completed the 1-month-postpartum assessment, 16 (21\%) met the criteria for $\mathrm{mMD}$.

\section{Feedback from the participants}

The follow-up questions were completed by most of the participants. Some referred to their datebooks and diaries to confirm specific facts. Comments made regarding the interviews with the participants included that the topics mentioned in the PDPI-R-J were practical and that they felt at ease talking about their feelings. They also mentioned that writing down their histories of depression made them feel comfortable communicating openly with the researchers.

\section{Distribution of risk factors}

Descriptive statistics for the PDPI-R-J (prenatal and postpartum versions) are reported in Table 3 . The most common risk factors in the prenatal version were prenatal anxiety and prenatal depression $(85.5 \%$ and 
Table 3 Risk factors during the 8 th months of pregnancy and the 1 st month postpartum $(\mathrm{N}=76)$

\begin{tabular}{|c|c|c|c|c|c|c|}
\hline PDPI-R-J & & 8th months pregnancy & & 1st month postpartum & & $t$ test or McNemar \\
\hline \multicolumn{7}{|c|}{ Prenatal Items } \\
\hline F1 & Being single, $\mathrm{n}(\%)$ & 0 & $(0.00)$ & 0 & $(0.00)$ & \\
\hline$F 2$ & Low socioeconomic status, n (\%) & 0 & $(0.00)$ & 0 & $(0.00)$ & \\
\hline F3 & Low self-esteem, mean (SD) & 0.51 & $(0.89)$ & 0.49 & $(0.83)$ & $p=0.69$ \\
\hline F4 & Prenatal depression, n (\%) & 18 & $(23.7)$ & 13 & $(17.1)$ & $p=0.18$ \\
\hline F5 & Prenatal anxiety, n (\%) & 65 & $(85.5)$ & 63 & $(82.9)$ & $p=0.75$ \\
\hline F6 & Pregnancy intendedness, mean (SD) & 0.37 & $(0.59)$ & 0.36 & $(0.56)$ & $p=0.82$ \\
\hline F7 & Prior depression, n (\%) & 14 & $(18.4)$ & 11 & $(14.5)$ & $p=0.45$ \\
\hline F8 & Lack of social support, mean (SD) & 2.29 & $(1.73)$ & 1.53 & $(1.7)$ & $p<0.01$ \\
\hline F9 & Marital dissatisfaction, mean (SD) & 0.36 & $(0.53)$ & 0.39 & $(0.71)$ & $p=0.63$ \\
\hline F10 & Life stress, mean (SD) & 0.87 & $(1.02)$ & 0.46 & $(0.70)$ & $p<0.01$ \\
\hline \multicolumn{7}{|c|}{ Postpartum items } \\
\hline F11 & Childcare stress, mean (SD) & & & 1.00 & $(0.8)$ & \\
\hline F12 & Infant temperament, mean (SD) & & & 1.50 & $(1.32)$ & \\
\hline F13 & Maternity blues, n (\%) & & & 44 & $(57.9)$ & \\
\hline
\end{tabular}

$23.7 \%$, respectively), and those in the postpartum version were prenatal anxiety, prenatal depression, and maternity blues $(82.9 \%, 17.1 \%$, and $57.9 \%$, respectively). No significant differences in age, employment status, educational level, or socioeconomic status were observed between the depressed and non-depressed groups.

To determine the relationship between the presence of each risk factor and the likelihood of having postpartum $\mathrm{mMD}$, we used bivariate logistic regression models. The postpartum mMD results at the $1^{\text {st }}$ month postpartum showed that marital dissatisfaction, childcare stress, and infant temperament were associated with having PPD. Table 4 reports the odds ratio (OR) for every risk factor in predicting PPD.

\section{Reliability of the PDPI-R}

Subscale correlation statistics were computed for the PDPI-R. All subscale-to-subscale correlations were either

Table 4 PDPI-R-J in predicting PPD: bivariate logistic analysis

\begin{tabular}{|c|c|c|c|c|c|}
\hline \multicolumn{2}{|l|}{ PDPI-R-J } & \multicolumn{2}{|c|}{ 8th months pregnancy } & \multicolumn{2}{|c|}{ 1st month postpartum } \\
\hline Prenatal items & OR & & $(95 \% \mathrm{Cl})$ & OR & $(95 \% \mathrm{Cl})$ \\
\hline F1 & Being single & & & & \\
\hline $\mathrm{F} 2$ & Low socioeconomic status & & & & \\
\hline F3 & Low self-esteem & 1.30 & $(0.73-2.30)$ & 1.54 & $(0.84-2.83)$ \\
\hline $\mathrm{F} 4$ & Prenatal depression & 2.40 & $(0.73-7.92)$ & 0.64 & $(0.13-3.21)$ \\
\hline F5 & Prenatal anxiety & * & & * & \\
\hline F6 & Pregnancy intendedness & 0.80 & $(0.29-2.19)$ & 0.83 & $(0.30-2.35)$ \\
\hline F7 & Prior depression & 1.67 & $(0.45-6.24)$ & 1.50 & $(0.35-6.46)$ \\
\hline F8 & Lack of social support & 1.21 & $(0.88-1.66)$ & 1.30 & $(0.96-1.76)$ \\
\hline F9 & Marital dissatisfaction & 1.83 & $(0.69-4.85)$ & 2.13 & $(1.05-4.34)$ \\
\hline F10 & Life stress & 1.09 & $(0.64-1.84)$ & 1.70 & $(0.82-3.52)$ \\
\hline \multicolumn{6}{|c|}{ Postpartum Items } \\
\hline F11 & Childcare stress & & & 3.39 & $(1.50-7.68)$ \\
\hline F12 & Infant temperament & & & 4.04 & $(1.74-9.37)$ \\
\hline F13 & Maternity blues & & & 2.63 & $(0.76-9.07)$ \\
\hline
\end{tabular}

*All of those who had prenatal anxiety (F5) met criteria for postpartum depression. 
Table 5 Spearman's correlations between factor-to-factor and factor-to-Total of PDPI-R-J prenatal version ( $N=76$ )

\begin{tabular}{|c|c|c|c|c|c|c|c|c|c|}
\hline & $\begin{array}{l}\text { Total } \\
\text { scale }\end{array}$ & F3 & F4 & F5 & F6 & F7 & F8 & F9 & F10 \\
\hline Total scale & 1 & & & & & & & & \\
\hline F3 & $0.588^{* *}$ & 1 & & & & & & & \\
\hline F4 & $0.337^{* *}$ & ns & 1 & & & & & & \\
\hline F5 & $0.253^{*}$ & ns & ns & 1 & & & & & \\
\hline F6 & $0.404^{* *}$ & $0.272^{*}$ & ns & ns & 1 & & & & \\
\hline F7 & $0.286^{*}$ & ns & $0.454^{* *}$ & ns & ns & 1 & & & \\
\hline F8 & $0.700^{* *}$ & $0.405^{* *}$ & ns & ns & Ns & ns & 1 & & \\
\hline F9 & $0.343^{* *}$ & ns & ns & ns & $0.298^{* *}$ & ns & ns & 1 & \\
\hline F10 & $0.700^{* *}$ & $0.241^{*}$ & $0.261^{*}$ & $0.279^{*}$ & $0.296^{* *}$ & ns & $0.260^{*}$ & $0.272^{*}$ & 1 \\
\hline
\end{tabular}

not significant or under 0.491 as shown in Tables 5 and 6. All subscale-to-total correlations were significant $(\mathrm{r}=0.25-0.70)$ except for that of factor 6, unintentional pregnancy. The internal consistency reliability of the PDPI-R was supported by Cronbach's alpha values of 0.68 for the prenatal version and 0.71 for the postpartum version.

\section{ROC analysis}

We analyzed the PDPI-R-J as a continuous measure. ROC analyses were performed in order to determine the cutoffs for the prenatal and postpartum versions of the PDPI-R-J. The prenatal version of the PDPI-R-J, which was administered at the $8^{\text {th }}$ month of pregnancy, allowed us to predict $62.8 \%$ of PPD cases accurately (Figure 1, Table 5; AUC $=0.628$ [95\% CI 0.48-0.77]; sensitivity = 0.56 and specificity $=0.57$ at a cutoff score of 5.5 ). For prenatal PDPI-R-J evaluated at baseline, the positive predictive value (PPV), negative predictive value (NPV), and misclassification rate (MR) were $0.28,0.85$, and $42.1 \%$, respectively. The postpartum version of the PDPI-R-J allowed us to predict $82.0 \%$ of PPD cases accurately (Figure 1, Table 5; AUC $=0.816$ [95\% CI $0.71-0.93$ ]; sensitivity $=0.81$ and specificity $=0.65$ at a cutoff score of 7.5). For the postpartum version of the PDPI-R-J, PPV, NPV, and MR were 0.33, 0.88, and $35.5 \%$, respectively.

A ROC analysis found that the logistic model of the PDPI-R-J postpartum version predicted $82 \%$ of PPD cases accurately (Figure 2; AUC $=0.816$ [95\% CI 0.7180.93]), whereas the logistic model of the PDPI-R-J postpartum version excluding three postpartum items (\#11-13) predicted 67\% of PPD cases (Figure 2; AUC = 0.671 [95\% CI 0.52-0.82]).

\section{Discussion}

The results of this study suggest that the PDPI-R-J is a useful and easy-to-administer instrument for assessment

Table 6 Spearman's correlations between factor-to-factor and factor-to-Total of PDPI-R-J postpartum version ( $\mathrm{N}=76$ )

\begin{tabular}{|c|c|c|c|c|c|c|c|c|c|c|c|c|}
\hline & Total scale & F3 & F4 & F5 & F6 & F7 & F8 & F9 & F10 & F11 & F12 & $\mathrm{F} 13$ \\
\hline Total scale & 1 & & & & & & & & & & & \\
\hline F3 & $0.343^{* *}$ & 1 & & & & & & & & & & \\
\hline $\mathrm{F} 4$ & $0.276^{*}$ & ns & 1 & & & & & & & & & \\
\hline F5 & $0.503^{* *}$ & ns & ns & 1 & & & & & & & & \\
\hline F6 & 0.171 & ns & ns & ns & 1 & & & & & & & \\
\hline F7 & $0.250^{*}$ & $0.336^{* *}$ & $0.310^{* *}$ & ns & ns & 1 & & & & & & \\
\hline F8 & $0.660^{* *}$ & $0.271^{*}$ & ns & $0.326^{* *}$ & ns & ns & 1 & & & & & \\
\hline F9 & $0.434^{* *}$ & ns & ns & ns & $0.257^{*}$ & ns & ns & 1 & & & & \\
\hline F10 & $0.517^{* *}$ & ns & $.270^{*}$ & ns & ns & ns & $0.280^{*}$ & $0.491^{* *}$ & 1 & & & \\
\hline F11 & $0.494^{* *}$ & ns & ns & $0.363^{* *}$ & ns & ns & ns & ns & ns & 1 & & \\
\hline $\mathrm{F} 12$ & $0.435^{* *}$ & ns & $-.251^{*}$ & $0.234^{*}$ & $-0.260^{*}$ & ns & ns & ns & ns & $0.440^{* *}$ & 1 & \\
\hline F13 & $0.324^{* *}$ & ns & ns & $0.250^{*}$ & ns & ns & ns & ns & ns & $0.226^{*}$ & ns & 1 \\
\hline
\end{tabular}




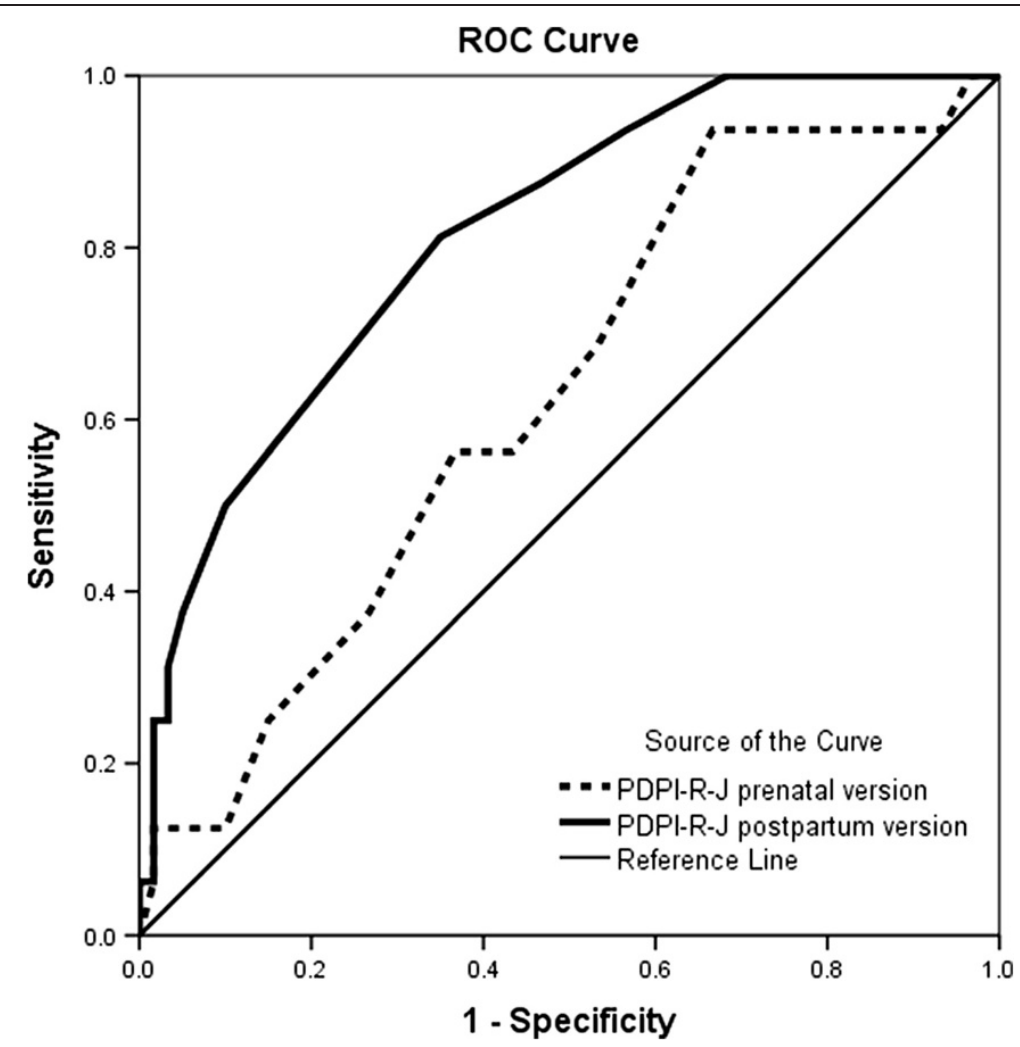

Figure 1 Receiver operating characteristic curve ofPDPI-R-J prenatal version vs. PDPI-R-J postpartum version predicting PPD.

of risk factors for PPD, in line with the results of the original instrument [24]. Our findings replicate previously published data that emphasize the roles of specific risk factors that occur both during pregnancy and in the postpartum period in predicting PPD. Feedback from the participants indicated that both they and the researcher recognized that their communication was enhanced through the use of the PDPI-R-J. Thus, the opportunity exists to help modify some of these factors before the baby is born. The PDPI-R-J ensures that we engage openly with the women to discuss issues and feelings about which they would not necessarily otherwise speak.

In our study, women reported increased anxiety and life stress and reduced social support during pregnancy, probably due to worry and concern about the imminent delivery. The results suggest that depression during pregnancy and lack of social support are associated with having PPD. These results are consistent with other reports $[34,35]$ that underline that depression during pregnancy and lack of social support usually predict poor adjustment after delivery. The analysis of risk factors conducted at the $1^{\text {st }}$ month after delivery emphasizes the role of childcare stress, infant temperament, low self-esteem, marital dissatisfaction, and other life stressors in predicting the likelihood of PPD. Reliability results were encouraging. The Cronbach's alpha values obtained were quite satisfactory for a new scale. It may be advisable for future investigations to confirm these results with larger numbers of participants.

The individual risk factors do not allow us to compute cumulative risk (i.e., the overall burden of psychiatric symptoms and distressing life experiences that may increase vulnerability to depression in the perinatal period). Total scores might be more informative than individual items for this purpose. Using the algorithm provided by the original instrument [24], we found that the cutoff score of 5.5 for the prenatal version of the PDPI-R administered at the $8^{\text {th }}$ month of pregnancy had very-similar results regarding sensitivity and specificity. This cutoff is lower than the value of 10.5 provided in the original article but higher than that of 3.5 proposed by Oppo et al. [26]. Cutoff scores can be different for different samples, especially when various cultural backgrounds are considered. Using the postpartum version of the PDPI-R-J, we were able to determine a cutoff score of 7.5 with a sensitivity of $69 \%$.

The prevalence of PPD in our study population was consistent with that identified in previous study [3]. A few women identified as "at risk of developing PPD" 


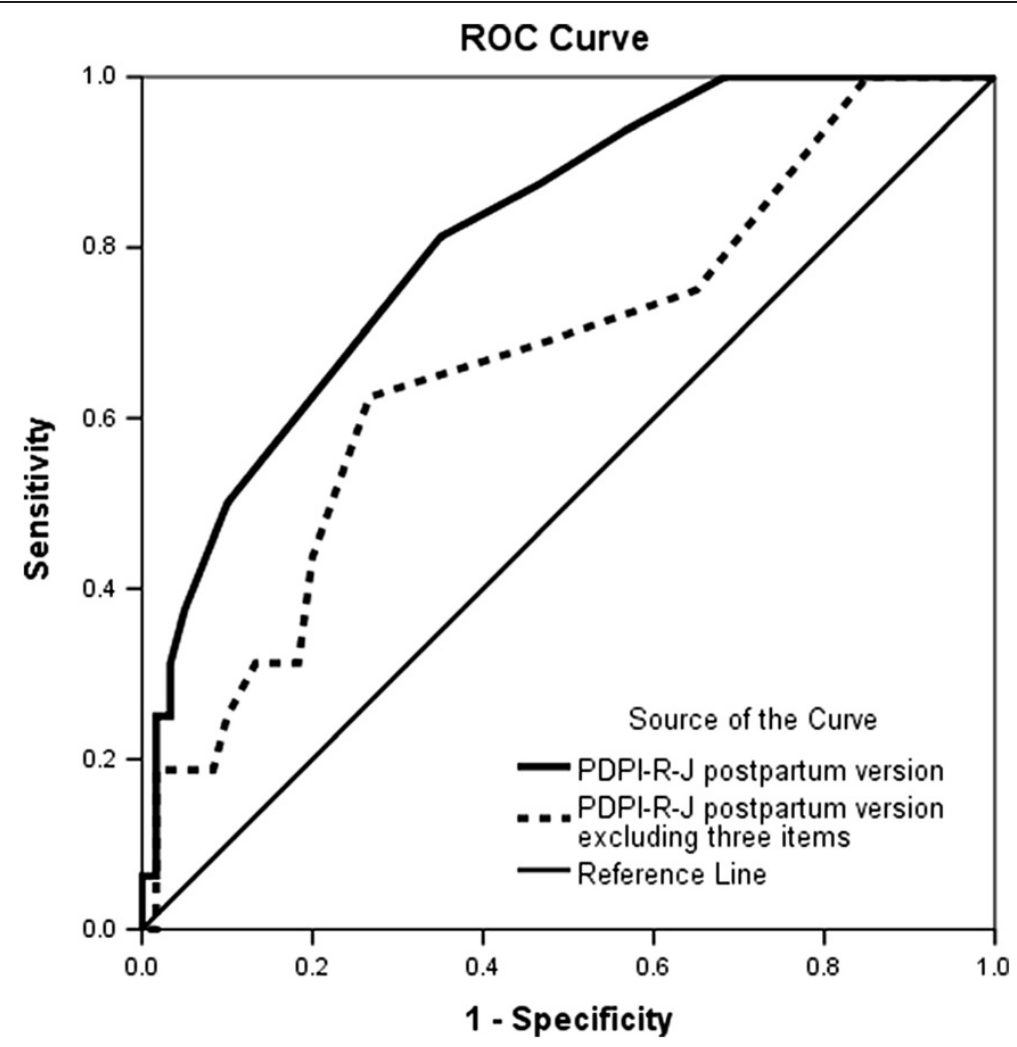

Figure 2 Receiver operating characteristic curve of PDPI-R-J postpartum version vs. PDPI-R-J postpartum version excluding three postpartum items predicting PPD.

were false positives in our study. It is well-known that when the prevalence in the population is low, PPV is less than $50 \%$ [36]. There might be controversy surrounding the routine use of screening for depression because of the potential that women "at risk of developing PPD" might not fall under the category. However, it seems that the case for screening outweighs that against it $[37,38]$. Specifically, screening for perinatal depression is likely to be useful because early intervention may also substantially benefit the woman's partner and infant [37].

The ROC analysis found that including postpartum items, such as factors related to infant care, increases the predictive validity of $\mathrm{mMD}$. This suggests that women who seemed to be at low risk during pregnancy still need to be tracked continuously in the postpartum period because their risk may depend on their delivery experience and their newborns' temperament.

The strengths of this study are its longitudinal design, its use of risk-factor assessment according to previously published psychometric properties, and the assessment of mMD using the M.I.N.I., a standardized psychiatric interview.

Several limitations of the study should also be considered. First, participants were recruited from one university hospital in the city area, and both their marital and socioeconomic statuses were uniform. Most of the women who participated had medium or high (86.8\%) socioeconomic status, significantly above-average for women in Japan (41.9\%) [39]; this could affect the external validity of our results. Second, the number of participants was very small, which could have led to insufficient statistical power to evaluate the effect of the subscale factors to predict PPD and to the predictive validity of the total PDPI-R-J scale. Third, the participants had higher levels of education than the average for Japanese women. The study population might have had a greater awareness of PPD, which could have driven the relatively high prevalence rate. Future research is needed to confirm the predictive validity of this measure in other samples with various characteristics.

Second, the number of participants was very small; this could have led to insufficient statistical power to evaluate differences between predictors of PPD.

\section{Conclusions}

A reliable instrument that can easily identify women with elevated risk of prenatal depression and PPD is the first key step to be taken in primary prevention to reduce the negative impact of this disorder on women, their infants, and their families. The results of our study 
show that the PDPI-R-J is a valid, feasible instrument for screening for PPD. We recommend the use of the PDPI$\mathrm{R}-\mathrm{J}$ in routine clinical practice both during pregnancy and in the postpartum period as a simple screening scale for depression. A total score can be assigned, and clinicians and researchers can evaluate the likelihood that any woman will develop PPD using the proposed cutoff score. Clinicians can also administer this PDPI-RJ to facilitate dialogue with women, as originally proposed for Japanese women [20].

\section{Competing interests}

The authors declare that they have no competing interests.

\section{Authors' contributions}

$\mathrm{Ml}$ contributed to the conceptualization and design of the study. MI contacted the original developer of the PDPI-R and took responsibility for the translation process of the instrument. Ml carried out data collection and analyses. The manuscript was drafted by MI. Both $\mathrm{MI}$ and KK reviewed and contributed to the submitted manuscript. Both authors read and approved the final manuscript.

\section{Acknowledgements}

We would like to thank Shiro Kozuma, PhD, MD, Eiko Otomo, RN, and Kyoko Honda, RN for their advice and comments on the development of the PDPI$R$ Japanese version. We would like to thank all the women who participated in this research. This project was supported by the Yamaji Fumiko Nursing Research Fund.

Received: 19 January 2013 Accepted: 2 May 2013

Published: 14 May 2013

\section{References}

1. Gavin NI, Gaynes BN, Lohr KN, Meltzer-Brody S, Gartlehner G, Swinson T: Perinatal depression: a systematic review of prevalence and incidence. Obstet Gynecol 2005, 106(5 Pt 1):1071-1083.

2. Vesga-Lopez O, Blanco C, Keyes K, Olfson M, Grant BF, Hasin DS: Psychiatric disorders in pregnant and postpartum women in the United States. Arch Gen Psychiatry 2008, 65(7):805-815.

3. Yamashita $\mathrm{H}$, Yoshida $\mathrm{K}$, Nakano $\mathrm{H}$, Tashiro N: Postnatal depression in Japanese women. Detecting the early onset of postnatal depression by closely monitoring the postpartum mood. J Affect Disord 2000, 58(2):145-154

4. Beck $C T$ : The lived experience of postpartum depression: a phenomenological study. Nurs Res 1992, 41(3):166-170.

5. Beck CT, Gable RK: Postpartum depression screening scale: development and psychometric testing. Nurs Res 2000, 49(5):272-282.

6. Records K, Rice M, Beck CT: Psychometric assessment of the postpartum depression predictors inventory-revised. J Nurs Meas 2007, 15(3):189-202

7. Blackmore ER, Carroll J, Reid A, Biringer A, Glazier RH, Midmer D, Permaul JA, Stewart DE: The use of the antenatal psychosocial health assessment (ALPHA) tool in the detection of psychosocial risk factors for postpartum depression: a randomized controlled trial. J Obstet Gynaecol Can 2006, 28(10):873-878

8. O'Hara MW, Schlechte JA, Lewis DA, Varner MW: Controlled prospective study of postpartum mood disorders: psychological, environmental, and hormonal variables. J Abnorm Psychol 1991, 100(1):63-73.

9. Braverman J, Roux J: Screening for the patient at risk for postpartum depression. Obstet Gynecol 1978, 52:731-736.

10. Petrick JM: Postpartum depression. Identification of high-risk mothers. JOGN Nurs 1984, 13(1):37-40.

11. Boyer D: Predictions of postpartum depression. Clinical Issues in Perinatal Women's Health Nurisng 1990, 1:359-368.

12. Appleby L, Gregoire A, Platz C, Prince M, Kumar R: Screening women for high risk of postnatal depression. J Psychosom Res 1994, 38(6):539-545.

13. Stamp GE, Williams AS, Crowther CA: Predicting postnatal depression among pregnant women. Birth 1996, 23(4):218-223.
14. Posner NA, Unterman RR, Williams KN, Williams GH: Screening for postpartum depression: an antepartum questionnaire. J Reprod Med 1997, 42:207-215

15. Reid A, Biringer A, Carroll J, Midmer D, Wilson L, Chalmers B, Stewart D: Using the ALPHA form in practice to assess antenatal psychosocial health. Antenatal psychosocial health assessment. CMAJ 1998, 159(6): 677-684.

16. Webster J, Pritchard MA, Creedy D, East C: A simplified predictive index for the detection of women at risk for postnatal depression. Birth 2003, 30:101-108.

17. Austin MP, Hadzi-Pavlovic D, Saint K, Parker G: Antenatal screening for the prediction of postnatal depression: validation of a psychosocial pregnancy risk questionnaire. Acta Psychiatr Scand 2005, 112(4):310-317.

18. Bernazzani O, Marks MN, Bifulco A, Siddle K, Asten P, Conroy S: Assessing psychosocial risk in pregnant/postpartum women using the contextual assessment of maternity experience (CAME)-recent life adversity, social support and maternal feelings. Soc Psychiatry Psychiatr Epidemiol 2005, 40(6):497-508

19. Boyce P, Hickery A, Gilchrist J, Talley NJ: The development of a brief personality scale to measure vulnerability to postnatal depression. Arch Womens Ment Health 2001, 3:147-153.

20. Beck CT: Revision of the postpartum depression predictors inventory. J Obstet Gynecol Neonatal Nurs 2002, 31(4):394-402

21. Beck CT: A meta-analysis of predictors of postpartum depression. Nurs Res 1996, 45(5):297-303

22. Beck CT: A meta-analysis of the relationship between postpartum depression and infant temperament. Nurs Res 1996, 45(4):225-230.

23. Beck CT: Predictors of postpartum depression: an update. Nurs Res 2001, 50(5):275-285

24. Beck CT, Records K, Rice M: Further development of the postpartum depression predictors inventory-revised. J Obstet Gynecol Neonatal Nurs 2006, 35(6):735-745.

25. Hanna B, Jarman H, Savage S, Layton K: The early detection of postpartum depression: midwives and nurses trial a checklist. J Obstet Gynecol Neonatal Nurs 2004, 33(2):191-197.

26. Oppo A, Mauri M, Ramacciotti D, Camilleri V, Banti S, Borri C, Rambelli C, Montagnani MS, Cortopassi S, Bettini A, et al: Risk factors for postpartum depression: the role of the postpartum depression predictors inventoryrevised (PDPI-R). results from the perinatal depression-research \& screening unit (PNDReScU) study. Arch Womens Ment Health 2009, 12(4):239-249.

27. Sugishita K, Kurihara K, Furuta M, Ikeda M, Yamamoto H, Ootsuka H, Kamibeppu K: Approach to perinatal mental health and child abuse prevention in Japanese perinatal centers. J Jpn Soc Perin Neon Med 2011 47(1):86-91

28. Declercq ER, Sakala C, Corry MP, Applebaum S: Listening to mothers II: report of the second national U.S. Survey of Women's childbearing experiences: conducted January-February, 2006 for childbirth connection by Harris interactive (R) in partnership with Lamaze international. J Perinat Educ 2007, 16(4):9-14.

29. Ministry of Health, Labour and Welfare: Prenatal visits and health checkups. Children and Family Bureau.1996, Declaration of Director, Publication No. 936, Nov. 20

30. Flaherty JA, Gaviria FM, Pathak D, Mitchell T, Wintrob R, Richman JA, Birz S: Developing instruments for cross-cultural psychiatric research. J Nerv Ment Dis 1988, 176(5):257-263.

31. Sheehan DV, Lecrubier $Y$, Sheehan $K H$, Amorim $P$, Janavs J, Weiller $E$, Hergueta T, Baker R, Dunbar GC: The mini-international neuropsychiatric interview (M.I.N.I.): the development and validation of a structured diagnostic psychiatric interview for DSM-IV and ICD-10. J Clin Psychiatry 1998, 59(Suppl 20):22-33. quiz 34-57.

32. Fletcher R, Fletcher S, Wagner E: Clinical epidemiology: the essentials. Baltimore: Williams \& Wilkins; 1996.

33. Swets J, Picket R: Evaluation of diagnostic systems. New York: Academic; 1982.

34. Glangeaud-Freudenthal NM, Boyce P: Postpartum depression: risk-factors and treatments-introduction. Arch Womens Ment Health 2003 6(Suppl 2):S31-S32.

35. Robertson E, Grace S, Wallington T, Stewart DE: Antenatal risk factors for postpartum depression: a synthesis of recent literature. Gen Hosp Psychiatry 2004, 26(4):289-295. 
36. Eberhard-Gran M, Eskild A, Tambs K, Schei B, Opjordsmoen S: The Edinburgh postnatal depression scale: validation in a Norwegian community sample. Nord J Psychiatry 2001, 55(2):113-117.

37. Buist $A E$, Barnett BE, Milgrom J, Pope $S$, Condon JT, Ellwood DA, Boyce PM Austin MP, Hayes BA: To screen or not to screen-that is the question in perinatal depression. Med J Aust 2002, 177(Suppl):S101-S105.

38. Milgrom J, Gemmill AW, Bilszta JL, Hayes B, Barnett B, Brooks J, Ericksen J, Ellwood D, Buist A: Antenatal risk factors for postnatal depression: a large prospective study. J Affect Disord 2008, 108(1-2):147-157.

39. Ministry of Health, Labour and Welfare: Comprehensive survey of living conditions. Tokyo: Comprehensive Survey of Living Conditions Office, Division SS; 2009.

doi:10.1186/1471-2393-13-112

Cite this article as: Ikeda and Kamibeppu: Measuring the risk factors for postpartum depression: development of the Japanese version of the Postpartum Depression Predictors Inventory-Revised (PDPI-R-J). BMC Pregnancy and Childbirth 2013 13:112.

\section{Submit your next manuscript to BioMed Central and take full advantage of:}

- Convenient online submission

- Thorough peer review

- No space constraints or color figure charges

- Immediate publication on acceptance

- Inclusion in PubMed, CAS, Scopus and Google Scholar

- Research which is freely available for redistribution 